\title{
Effects of acute versus repeated cocaine exposure on the expression of endocannabinoid signaling-related proteins in the mouse cerebellum
}

\section{Ana Palomino ${ }^{1+}$, Francisco-Javier Pavón ${ }^{1+}$, Eduardo Blanco-Calvo ${ }^{1,2+}{ }^{+}$Antonia Serrano ${ }^{1}$, Sergio Arrabal ${ }^{1}$, Patricia Rivera ${ }^{1}$, Francisco Alén ${ }^{3}$, Antonio Vargas ${ }^{1}$, Ainhoa Bilbao ${ }^{4}$, Leticia Rubio $^{5}$, Fernando Rodríguez de Fonseca ${ }^{1}$ * and Juan Suárez ${ }^{1}$ *}

\author{
' Laboratorio de Investigación (Unidad de Gestión Clínica de Salud Mental), Instituto de Investigación Biomédica de Málaga, Hospital Regional \\ Universitario de Málaga, Málaga, Spain \\ 2 Departament de Pedagogia i Psicologia, Facultat de Ciències de I'Educació, Universitat de Lleida, Lleida, Spain \\ ${ }^{3}$ Departamento de Psicobiología, Facultad de Psicología, Universidad Complutense, Madrid, Spain \\ ${ }^{4}$ Institute of Psychopharmacology, Central Institute of Mental Health, Medical Faculty of Mannheim, University of Heidelberg, Mannheim, Germany \\ ${ }^{5}$ Departamento de Anatomía y Medicina Legal y Forense, Facultad de Medicina, Universidad de Málaga, Málaga, Spain
}

\section{Edited by:}

Marisa Roberto, The Scripps Research Institute, USA

\section{Reviewed by:}

Massimo Ubaldi, University of Camerino, Italy

Eliot Lawrence Gardner, National Institute on Drug Abuse - National Institutes of Health - U.S. Public Health Service, USA

\section{*Correspondence:}

Fernando Rodríguez de Fonseca and Juan Suárez, Laboratorio de Investigación (Unidad de Gestión Clínica de Salud Mental), Instituto de Investigación Biomédica de Málaga, Hospital Regional Universitario de Málaga, Avenida Carlos Haya 82, Pabellón de Gobierno, 29010 Málaga, Spain

e-mail: fernando.rodriguez@ fundacionimabis.org: juan.suarez@ibima.eu

${ }^{\dagger}$ Ana Palomino, Francisco-Javier Pavón and Eduardo Blanco-Calvo have contributed equally to this work.
Growing awareness of cerebellar involvement in addiction is based on the cerebellum's intermediary position between motor and reward, potentially acting as an interface between motivational and cognitive functions. Here, we examined the impact of acute and repeated cocaine exposure on the two main signaling systems in the mouse cerebellum: the endocannabinoid (eCB) and glutamate systems. To this end, we investigated whether eCB signaling-related gene and protein expression \{cannabinoid receptor type 1 receptors and enzymes that produce [diacylglycerol lipase alpha/beta (DAGL $\alpha / \beta)$ and $N$-acyl phosphatidylethanolamine phospholipase D (NAPE-PLD)] and degrade [monoacylglycerol lipase (MAGL) and fatty acid amino hydrolase (FAAH)] eCB\} were altered. In addition, we analyzed the gene expression of relevant components of the glutamate signaling system [glutamate synthesizing enzymes liver-type glutaminase isoform (LGA) and kidney-type glutaminase isoform (KGA), metabotropic glutamatergic receptor (mGluR3/5), NMDAionotropic glutamatergic receptor (NR1/2A/2B/2C) and AMPA-ionotropic receptor subunits (GluR1/2/3/4)] and the gene expression of tyrosine hydroxylase (TH), the rate-limiting enzyme in catecholamine biosynthesis, because noradrenergic terminals innervate the cerebellar cortex. Results indicated that acute cocaine exposure decreased DAGL $\alpha$ expression, suggesting a down-regulation of 2-arachidonylglycerol (2-AG) production, as well as gene expression of TH, KGA, mGluR3 and all ionotropic receptor subunits analyzed in the cerebellum. The acquisition of conditioned locomotion and sensitization after repeated cocaine exposure were associated with an increased NAPE-PLD/FAAH ratio, suggesting enhanced anandamide production, and a decreased DAGL $\beta / M A G L$ ratio, suggesting decreased 2-AG generation. Repeated cocaine also increased LGA gene expression but had no effect on glutamate receptors. These findings indicate that acute cocaine modulates the expression of the eCB and glutamate systems. Repeated cocaine results in normalization of glutamate receptor expression, although sustained changes in eCB is observed. We suggest that cocaine-induced alterations to cerebellar eCB should be considered when analyzing the adaptations imposed by psychostimulants that lead to addiction.

Keywords: cocaine, sensitization, cannabinoid, glutamate, tyrosine hydroxylase, mouse, cerebellum

\section{INTRODUCTION}

The neurobiological mechanisms underlying the formation, maintenance and retrieval of drug-related behaviors have been associated with a neuroanatomical circuit to which

Abbreviations: 2-AG, 2-arachidonylglycerol; AEA, anandamide; CB1, cannabinoid receptor type 1; CL, conditioned locomotion; $\mathrm{CPP}$, conditioned place preference; CS, cocaine sensitization; DA, dopamine; DAGL $\alpha / \beta$, diacylglycerol lipase alpha/beta; eCBs, endocannabinoids; FAAH, fatty acid amino hydrolase; GluR1/2/3/4, AMPA-ionotropic glutamatergic receptor; Hc, hippocampus; KGA, kidney-type the contribution of the cerebellum is not considered. Reward-associated conditioned behaviors are controlled by dopamine (DA)-glutamate interactions in regions of the

glutaminase isoform; LGA, liver-type glutaminase isoform; MAGL, monoacylglycerol lipase; $\mathrm{mGluR}$, metabotropic glutamatergic receptor; NAc, nucleus accumbens; NAE, $N$-acylethanolamine; NAPE-PLD, $N$-acyl phosphatidylethanolamine phospholipase D; NR1/2A/2B/2C, NMDA-ionotropic glutamatergic receptor; $\mathrm{PFCx}$, prefrontal cortex; RT-qPCR, reverse-transcription real-time quantitative-polymerase chain reaction; Str, dorsal striatum. 
mesolimbic pathway, such as the ventral tegmental area (VTA), nucleus accumbens (NAc), prefrontal cortex (PFCx), dorsal striatum (Str), hippocampus (Hc) and others (Bower and Parsons, 2003). Neuromodulatory systems, such as the endocannabinoid (eCB) signaling system, participate in the control of the DAglutamate interactions that sustain drug-associated conditioning. Thus, the presence of $\mathrm{eCB}$ in these brain pathways has been implicated in the neurochemical and behavioral effects of psychostimulants (Gorriti et al., 1999; De Vries and Schoffelmeer, 2005; Maldonado etal., 2006). Endocannabinoid production is triggered by the activation of DA D2 receptors (Giuffrida et al., 1999). These endocannabinoids modulate synaptic plasticity through stimulation of cannabinoid receptor type 1 (CB1) receptors located in the PFCx glutamatergic axon terminals that innervate the Str (Gerdeman etal., 2002; Freund et al., 2003; Piomelli, 2003; Ronesi and Lovinger, 2005; Mathur et al., 2013). Chronic drug abuse produces a re-organization (neuroadaptation) of the prefronto-striatal-limbic network via its effect on neurotransmitter and neuromodulator systems and their functional interactions (Nestler, 2005; Noori et al., 2012). Outside this circuit, the cerebellum has a relevant catecholaminergic innervation that modulates glutamatergic transmission. However, there is no study addressing the interactions between these two signaling systems in the cerebellum in the context of addiction.

It is becoming clear that the cerebellum plays a potential intermediary role between different brain areas involved in drug-related behavior, such as the prefrontal and associative non-motor cortices, the basal ganglia and the limbic system (Heath et al., 1978; Bostan and Strick, 2010). Moreover, the medial part of the cerebellum has bidirectional connections with dopaminergic VTA neurons (Schweighofer et al., 2004). All of these anatomical findings challenge the traditional view of the cerebellum and support its involvement in functional networks affected by drug addiction (Miquel et al., 2009).

Considering both the anatomical relationship of the cerebellum with major brain pathways involved in drug addiction and the existence of a network of noradrenergic projections to the cerebellar cortex on which cocaine might act, it is reasonable to think that acute/chronic cocaine use might have an impact on the main cerebellar transmission systems. Previous works have demonstrated that cocaine modulates not only dopaminergic activity but also norepinephrine- and serotonin-mediated actions in the brain (Pitts and Marwah, 1987). Thus, the action of cocaine in noradrenergic target circuits could also contribute to the behavioral response. Elevated catecholamine transmission is a primary mediator of cocaine addiction, and repeated exposure to cocaine is associated with the recruitment of glutaminase expression and glutamatergic transmission (Glowinski and Axelrod, 1965; Cornish and Kalivas, 2000; Malenka and Bear, 2004; Lopez-Moreno et al., 2008; Ruiz et al., 2010; Blanco et al., 2012). Regarding the cerebellum, the potentiating effects of cocaine on the GABAmediated inhibition of Purkinje neurons were not observed after the selective depletion of noradrenergic neurons (Waterhouse et al., 1991). Moreover, cocaine-induced sensitization augmented the expression of cFos, jun-B, Homer $1 \mathrm{~b} / \mathrm{c}$ and Homer $3 \mathrm{a} / \mathrm{b}$ in the cerebellar cortex (Couceyro et al., 1994; Jiménez-Rivera et al.,
2000; Dietrich et al., 2007). These homer isoforms could be a crucial link between mGluR and $\mathrm{IP}_{3}$-dependent intracellular $\mathrm{Ca}^{2+}$ signaling, which are considered relevant steps for synaptic remodeling and long-term adaptive changes (Szumlinski et al., 2006). In addition, during the withdrawal period from repeated cocaine exposure, the levels of NR1 and NR2A-NMDA glutamate receptor subunits were reduced in rat cerebellum (Yamaguchi et al., 2002).

Classic studies (Giuffrida et al., 1999; Gorriti et al., 1999) established that both the blockade and desensitization of CB1 receptors facilitate psychostimulant actions. Recent studies (Mereu et al., 2013) indicate that the eCB signaling system is recruited at first cocaine administration to initiate plastic changes that lead to the onset of behavioral sensitization. These plastic changes have been shown in the prefrontocortical projections to basal ganglia neurons. However, there are no available data on the impact of cocaine combined with the induction of sensitization on the expression of the signaling machinery for endocannabinoids and glutamate. Because the interaction of catecholaminergic innervation on excitatory synapsis in the brain has been shown to be dependent on endocannabinoid signaling, we decided to investigate whether similar interactions occur in the cerebellum after repeated cocaine exposure. To this end, we investigated whether gene and protein expression of relevant components of the eCB, glutamate signaling system (receptors and synthesis/degradation enzymes) or the rate-limiting enzyme in catecholamine biosynthesis (tyrosine hydroxylase) were altered by acute cocaine administration. We also investigated whether these factors were altered after a cocaine sensitization (CS) regimen involving cocaine administration into the mouse cerebellum.

\section{MATERIALS AND METHODS ETHICS STATEMENT}

The protocols for animal care and use were approved by the Ethics and Research Committee at the Hospital Carlos Haya and Universidad de Málaga. All experimental animal procedures were carried out in strict accordance with the European Communities directive 86/609/ECC (24 November 1986) and Spanish legislation (BOE 252/34367-91, 2005) regulating animal research. All efforts were made to minimize animal suffering and to reduce the number of animals used.

\section{ANIMALS AND HOUSING}

We used male C57BL/6J mice (25 $\pm 5 \mathrm{~g}$; Charles River Laboratories International, Wilmington, MA, USA) for behavioral procedures and gene and protein expression analyses. All animals were maintained at the vivarium of the University of Malaga. All animals were experimentally naïve and were housed in clear plastic cages in a temperature-controlled room $\left(22 \pm 2^{\circ} \mathrm{C}\right)$ with a $12 \mathrm{~h}$ light-dark cycle (lights on at 8:00 a.m.) with free access to Purina laboratory feed and tap water before the initiation of the experiments.

\section{DRUGS}

Cocaine-HCl was obtained from Alkaliber S.A. (Madrid, Spain), dissolved in sterile saline $(0.9 \% \mathrm{NaCl})$ just before experimentation, and administered intraperitoneally at doses of 10 (acute and priming) and $20 \mathrm{mg} / \mathrm{kg}$ (cocaine conditioning). 


\section{APPARATUS AND GENERAL PROCEDURES}

All mice were handled and habituated to the injection procedures once per day for 5 days prior to behavioral testing to reduce the effect of the non-specific stress of being handled on test behavior. All experiments were carried out between 08:00 and 20:00 h. The animals were acclimated to the experimental room for $30 \mathrm{~min}$ each day. Performance in the open field was recorded by a computedbased video tracking system (Smart v2.5 ${ }^{\circledR}$, Panlab, Barcelona, Spain). The maximum light intensity in the center of the open field was 100 lux. Four open fields $(50 \mathrm{~cm} \times 50 \mathrm{~cm} \times 50 \mathrm{~cm}$, Panlab) with gray backgrounds were used. The animals were placed in the center of the arena, and their behavior was recorded for $30 \mathrm{~min}$. Horizontal locomotion was measured as total distance traveled $(\mathrm{cm})$.

\section{ACUTE/REPEATED COCAINE ADMINISTRATION, CONDITIONED LOCOMOTION, AND COCAINE SENSITIZATION}

Cocaine sensitization was conducted following a consecutive fourphase paradigm: cocaine conditioning, drug free period (resting), conditioned locomotion (CL) probe and CS or priming test. Firstly, two mouse groups were injected with cocaine $(20 \mathrm{mg} / \mathrm{kg}$ body weight) or vehicle $(0.9 \% \mathrm{NaCl})$ for five consecutive days and exposed to the open field (cocaine conditioning). For the next 5 days, all animals rested without the drug. Then, we evaluated the locomotor activity response induced by the association between repeated administration of cocaine and the location at which it exerted its stimulant effect by simulated administration with vehicle (CL response). On the last day, we assessed the presence of sensitization by lower-dose cocaine administration (priming: $10 \mathrm{mg} / \mathrm{kg}$ body weight). All animals were evaluated in the Open Field test to measure the distance traveled $(\mathrm{cm})$ for $30 \mathrm{~min}$ with the video tracking system, except in the drug free period. There were four experimental groups $(n=8)$ : animals that were conditioned with cocaine $(20 \mathrm{mg} / \mathrm{kg}$ body weight $)$ for 5 days (chronic pretreatment), rested for 5 days and were administered vehicle or cocaine $(10 \mathrm{mg} / \mathrm{kg}$ body weight; acute treatment) and animals that were conditioned with vehicle for 5 days (chronic pretreatment), rested for 5 days, and then were treated with vehicle or cocaine $(10 \mathrm{mg} / \mathrm{kg}$ body weight; acute treatment). Thus, the groups of animals were $(n=8)$ : (1) chronic vehicle pretreatment and acute vehicle treatment (vehiclevehicle group), (2) chronic vehicle pretreatment and acute cocaine treatment (vehicle-cocaine group), (3) chronic cocaine pretreatment and acute vehicle treatment (cocaine-vehicle group), and (4) chronic cocaine pretreatment and acute cocaine treatment (cocaine-cocaine group). Animals from these four groups were used for the behavioral studies and the gene and protein expression analyses.

\section{TISSUE COLLECTION}

One hour after acute treatment with vehicle or cocaine, all animals were sacrificed by decapitation, and their brains were immediately dissected out, frozen on dry ice, and stored at $-80^{\circ} \mathrm{C}$. The brains were dissected in coronal brain slice sections ( $1 \mathrm{~mm}$ thick) on dry ice using razor blades and a mouse brain slicer matrix (Zivic Instruments). The cerebellar cortex was precisely removed with fine surgical instruments according to the Paxinos and Franklin
(2004). Samples were stored at $-80^{\circ} \mathrm{C}$ until they were used for gene and protein analyses.

\section{RNA ISOLATION AND QUANTITATIVE REAL-TIME PCR ANALYSIS}

Real-time PCR was used to quantify the relative mRNA levels of the catecholamine synthesizing enzyme tyrosine hydroxylase $(\mathrm{TH})$ and the relevant receptors and synthesis/degradation enzymes involved in eCB signaling [CB1 receptor, $N$-acyl phosphatidylethanolamine phospholipase D (NAPE-PLD), diacylglycerol lipase alpha/beta (DAGL $\alpha / \beta)$, monoacylglycerol lipase (MAGL) and fatty acid amino hydrolase (FAAH)] and glutamate signaling [liver-type glutaminase isoform (LGA), kidney-type glutaminase isoform (KGA), mGluR3/5 metabotropic receptors, and NR1/2A/2B/2C-NMDA and GluR1/2/3/4- (AMPA ionotropic receptor subunits)] in the cerebellum. Total RNA was isolated using the Trizol ${ }^{\circledR}$ method, according to the manufacturer's instruction (Gibco BRL Life Technologies, Baltimore, MD, USA). The tissue was placed into $1 \mathrm{ml}$ of Trizol Reagent (Invitrogen, Carlsbad, CA, USA) and homogenized with an IKA-Ultra-Turrax ${ }^{\circledR}$ T8 (IKA-Werke GmbH, Staufen, Germany). To ensure the purity of the mRNA sequences and exclude molecules smaller than 200 nucleotides, RNA samples were isolated with a RNeasy Minelute Cleanup Kit (Qiagen, Hilden, Germany), which included digestion with DNase I column (RNase-free DNase Set, Qiagen), according to the manufacturers' instructions, and purified using RNeasy Mini Kit (Qiagen, Hilden, Germany). The total mRNA concentrations were quantified using a spectrophotometer (Nanodrop 1000 Spectrophotometer, Thermo Scientific, Rochester, NY, USA) to ensure A260/280 ratios of 1.8-2.0.

Reverse-transcription was carried out with $2 \mu \mathrm{g}$ of mRNA using the Transcriptor Reverse Transcriptase kit and random hexamer primers (Transcriptor RT, Roche Diagnostic GmbH, Manheim, Germany). Negative controls included reverse-transcription reactions that omitted reverse transcriptase. The resultant cDNAs were used as templates for quantitative real-time PCR with an iCycler system (BioRad, Hercules, CA, USA) using the Quanti-Test SYBR Green PCR kit (Qiagen, Hilden, Germany). The primers used are described in Table 1. Oligonucleotides were provided by Sigma-Proligo (Proligo France SAS, Paris, France).

Quantification was carried out according to standard curves and was run simultaneously. The samples for each reaction were run in duplicate. The PCR product was separated by electrophoresis in a $1 \%$ agarose gel to verify fragment size and the absence of contaminating fragments, quantified by measuring the absorbance at $260 \mathrm{~nm}$, and serially diluted to $10^{-5} \mathrm{pg} / \mathrm{ml}$. Several 10 -fold dilutions $\left(10^{-1}-10^{-5}\right)$ were checked for optimal cycling on the iClycler system, and three of them were selected for the standard curves. Each reaction was run in duplicate and contained $2.5 \mu \mathrm{l}$ of cDNA template, $8 \mu \mathrm{l}$ of Master SYBR Green, $4.86 \mu \mathrm{l}$ of PCR Ultra Pure Water and $0.64 \mu \mathrm{l}$ of primers in a final reaction volume of $15 \mu \mathrm{l}$. Cycling parameters were $95^{\circ} \mathrm{C}$ for $15 \mathrm{~min}$ to activate DNA polymerase, then $30-40$ cycles at $94^{\circ} \mathrm{C}$ for $15 \mathrm{~s}$, temperaturespecific annealing for each primer for $30 \mathrm{~s}$ and a final extension step of $72^{\circ} \mathrm{C}$ for $30 \mathrm{~s}$, in which fluorescence was acquired. Melting curve analysis was performed to ensure that only a single product was amplified. Absolute values from each sample were normalized with regard to $\beta$-actin mRNA (constitutive gene), which was used 
Table 1 | Primers sequences used for RT-PCR ${ }^{1}$.

\begin{tabular}{|c|c|c|c|c|c|}
\hline & Gene ID & $\begin{array}{l}\text { GenBank accession } \\
\text { numbers }\end{array}$ & Forward sense primers & Reverse antisense primers & $\begin{array}{l}\text { Product size } \\
\text { (bp) }\end{array}$ \\
\hline & $\mathrm{TH}$ & NM_009377.1 & ccaaggaaagtgtcagagttgg & accctgcttgtattggaagg & 150 \\
\hline \multirow[t]{5}{*}{$\mathrm{eCB}$} & Cnr1 (CB1 receptor) & NM_007726.1 & gctgcaatctgtttgctcag & ttgccatcttctgaggtgtg & 201 \\
\hline & Faah (FAAH) & NM_010173.2 & cggagagtgactgtgtggtg & tcagtgcctaaacccagagg & 220 \\
\hline & Mgll (MAGL) & NM_011844.3 & catggagctggggaacactg & ggagatggcaccgcccatggag & 240 \\
\hline & Dagla (DAGL $\alpha)$ & NM_198114.1 & agaatgtcaccctcggaatg & gcaggttgtaagtccgcaaa & 153 \\
\hline & Daglb (DAGL $\beta)$ & NM_144915.2 & aagcggccagatacattcac & ggataagcgacacgacaaag & 246 \\
\hline Glutamate sinthesizing & Gls2 (LGA) & NM_001033264 & ttggaccatgcgctgcatcttg & gcactcggatcatgacgcctcac & 190 \\
\hline NMDA ionotropic glutamate & Grin1 (NR1) & NM_008169 & gtgcaagtgggcatctacaa & tgggcttgacatacacgaag & 157 \\
\hline \multirow[t]{3}{*}{ receptor subunits } & Grin2a (NR2A) & NM_008170 & gtttgttggtgacggtgaga & aagaggtgctcccagatgaa & 180 \\
\hline & Grin2b (NR2B) & NM_008171 & atgtggattgggaggatagg & tcgggctttgaggatacttg & 249 \\
\hline & Grin2c (NR2C) & NM_010350 & ggaatggtatgatcggtgag & ccgtgaggcacattacaaac & 225 \\
\hline AMPA ionotropic glutamate & Gria1 (GluR1) & NM_008165.2 & ttttctaggtgcggttgtgg & cctttggagaactgggaaca & 210 \\
\hline \multirow[t]{3}{*}{ receptor subunits } & Gria2 (GluR2) & NM_001039195.1 & aaggaggaaagggaaacgag & ccgaagtggaaaactgaacc & 217 \\
\hline & Gria3 (GluR3) & NM_016886.2 & caacaccaaccagaacacca & atcggcatcagtgggaaa & 229 \\
\hline & Gria4 (GluR4) & NM_019691.3 & ttggaatgggatggtaggag & taggaacaagaccacgctga & 250 \\
\hline
\end{tabular}

${ }^{1}$ Oligonucleotides were provided by Sigma-Proligo.

as a reference standard. This internal standard was chosen based on a first analysis of a panel of housekeeping genes that included cyclophylin and transcription factor (specificity protein) 1 .

\section{WESTERN BLOT ANALYSIS}

Western blotting was used to quantify the relative protein levels of the eCB signaling system (CB1 receptor, NAPE-PLD, DAGL $\alpha / \beta$, MAGL, and FAAH) in the cerebellum. Samples were homogenized in $50 \mathrm{mM}$ Hepes buffer ( $\mathrm{pH} 8$ ) and $0.32 \mathrm{M}$ sucrose buffer to obtain membrane protein extracts. The homogenate was centrifuged at $800 \mathrm{~g}$ for $10 \mathrm{~min}$ at $4^{\circ} \mathrm{C}$, and the supernatant was centrifuged at $40000 \mathrm{~g}$ for $30 \mathrm{~min}$. The pellets were resuspended in $50 \mathrm{mM}$ Hepes buffer ( $\mathrm{pH} 8$ ) and pulverized using a homogenizer. Protein concentration was measured using the Bradford protein assay.

For immunoblotting, protein samples $(40 \mu \mathrm{g})$ were separated on $10 \%(\mathrm{w} / \mathrm{v})$ SDS-PAGE gels, transferred on to nitrocellulose membranes (BioRad) and controlled by Ponceau Red staining. After blocking with $5 \%(\mathrm{w} / \mathrm{v})$ bovine serum albumin (BSA) in PBST buffer $(0.1 \%$ Tween 20 in PBS) at room temperature for $1 \mathrm{~h}$, membranes were incubated with the primary antibodies overnight at $4^{\circ} \mathrm{C}$, as was described previously (Suarez et al., 2008): anti-CB1 receptor (Cayman, cat. no. 101500) diluted 1:200, anti-DAGL $\alpha$ (produced in our laboratory) diluted 1:100, antiDAGL $\beta$ (produced in our laboratory) diluted 1:100, anti-NAPEPLD (produced in our laboratory) diluted 1:100, anti-FAAH (Cayman, cat. no. 101600) diluted 1:100 and anti-MAGL
(Cayman, cat. no. 100035) diluted 1:200. After incubation with a peroxidise-conjugated goat anti-rabbit $\operatorname{IgG}(\mathrm{H}+\mathrm{L})$ antibody (Promega) diluted 1:2500 for $1 \mathrm{~h}$ at room temperature, the membranes were revealed by the Western Blotting Luminol Reagent kit (Santa Cruz Biotechnology). Specific protein bands were visualized and quantified by chemiluminescence using an imaging AutoChemi ${ }^{\text {TM }}$ UVP BioImagin System (LTF Labortechnik). $\beta$-actin was quantified and used as a loading control (anti- $\beta$-actin, Sigma, cat. no. A5316, diluted 1:1000).

\section{STATISTICAL ANALYSIS}

Data are expressed as the mean \pm standard error of the mean (SEM) for at least eight determinations per experimental group. Statistical significance for behavioral data was assessed by oneway/repeated measures analysis of variance (ANOVA) and a post hoc Newman-Keuls test. Statistical significance of gene and protein quantification was obtained by two-way ANOVA with the two factors being chronic pretreatment (conditioning with vehicle or cocaine for 5 days) and acute treatment (vehicle or cocaine for 1 day), followed by Bonferroni test as a priori non-orthogonal contrast test. $P<0.05$ was considered statistically significant.

\section{RESULTS \\ COCAINE-ASSOCIATED BEHAVIORS}

Figure 1A shows a schematic representation of the schedule used for analysis of cocaine-associated behaviors. Briefly, it 
included the analysis of locomotion in the open field during repeated cocaine administration (5 days-cocaine conditioning), a 5 days-resting period, 1 day for testing CL and 1 day for testing CS (priming). Mice pretreated with vehicle for 5 days, rested and then treated with vehicle (vehicle-vehicle group) were used as the baseline for locomotion (Figure 1B). Mice pretreated with vehicle and then treated with one administration of cocaine $(10 \mathrm{mg} / \mathrm{kg}$; vehicle-cocaine group) showed a significant increase in locomotor activity $\left({ }^{* * *} P<0.001\right)$ compared with the vehicle-vehicle group. After 5 days of cocaine conditioning $(20 \mathrm{mg} / \mathrm{kg})$ and 5 days of resting, animals were then subjected to an administration of vehicle or cocaine $(10 \mathrm{mg} / \mathrm{kg})$. Repeated cocaine-conditioned animals receiving vehicle (cocainevehicle group) showed an increase in locomotion, reflecting the acquisition of a CL response $\left({ }^{* * *} P<0.001\right)$ compared with the vehicle-vehicle group (non-conditioned control group). This effect was produced by association between the features of the environment and the rewarding properties of cocaine after 5 days of injections. Repeated cocaine-conditioned animals receiving cocaine (cocaine-cocaine group) showed a significant CS response as a consequence of significantly higher locomotor activity compared with the conditioning vehicle groups (vehicle-vehicle, ${ }^{* * *} P<0.001$ and vehicle-cocaine, $\left.{ }^{\# \#} P<0.01\right)$. Moreover, CSassociated locomotor activity (cocaine-cocaine group) was significantly higher $(\$ \$ P<0.001)$ than $C L$ (cocaine-vehicle group; Figure 1B).

\section{GENE EXPRESSION OF CATECHOLAMINE BIOSYNTHESIS}

To address whether cocaine treatment was associated with alterations in the state of the catecholaminergic system, we analyzed the gene expression of $\mathrm{TH}$, the rate-limiting enzyme in catecholamine biosynthesis, in the cerebellum of the vehiclevehicle $(\mathrm{V}-\mathrm{V})$, vehicle-cocaine $(\mathrm{V}-\mathrm{C})$, cocaine-vehicle $(\mathrm{C}-\mathrm{V})$, and cocaine-cocaine (C-C) mice. Acute cocaine exposure (vehiclecocaine group) induced a decrease in $\mathrm{TH}$ gene expression $\left({ }^{*} P<0.05\right)$ compared with the vehicle-vehicle group (Figure 1C). Repeated cocaine-conditioned animals receiving vehicle (cocainevehicle group) or cocaine (cocaine-cocaine group) did not show any effect on $\mathrm{TH}$ expression derived from acute treatment, chronic pre-treatment or the interaction between these factors.

\section{GENE AND PROTEIN EXPRESSION OF ECB SIGNALING COMPONENTS}

To address the possible neuroadaptive changes in relevant components of $\mathrm{eCB}$ signaling associated with the effects of acute cocaine exposure and cocaine conditioning or sensitization, we analyzed the gene and protein expression of $\mathrm{CB} 1$ receptors and the enzymes of eCB synthesis (DAGL $\alpha / \beta$ and NAPE-PLD) and degradation (FAAH and MAGL) in the cerebellum of vehiclevehicle $(\mathrm{V}-\mathrm{V})$, vehicle-cocaine $(\mathrm{V}-\mathrm{C})$, cocaine-vehicle $(\mathrm{C}-\mathrm{V})$, and cocaine-cocaine $(\mathrm{C}-\mathrm{C})$ mice. To analyze whether the differential expression of either $\mathrm{eCB}$ producing or degrading enzymes can result in altered $\mathrm{eCB}$ tone in the cerebellum in the four experimental groups, we also calculated the ratios between NAPE-PLD and FAAH expression and between DAGL $\alpha / \beta$ and MAGL expression. These ratios can suggest possible changes in $N$-acylethanolamines (NAEs) and 2-arachidonylglycerol (2-AG) levels, respectively.

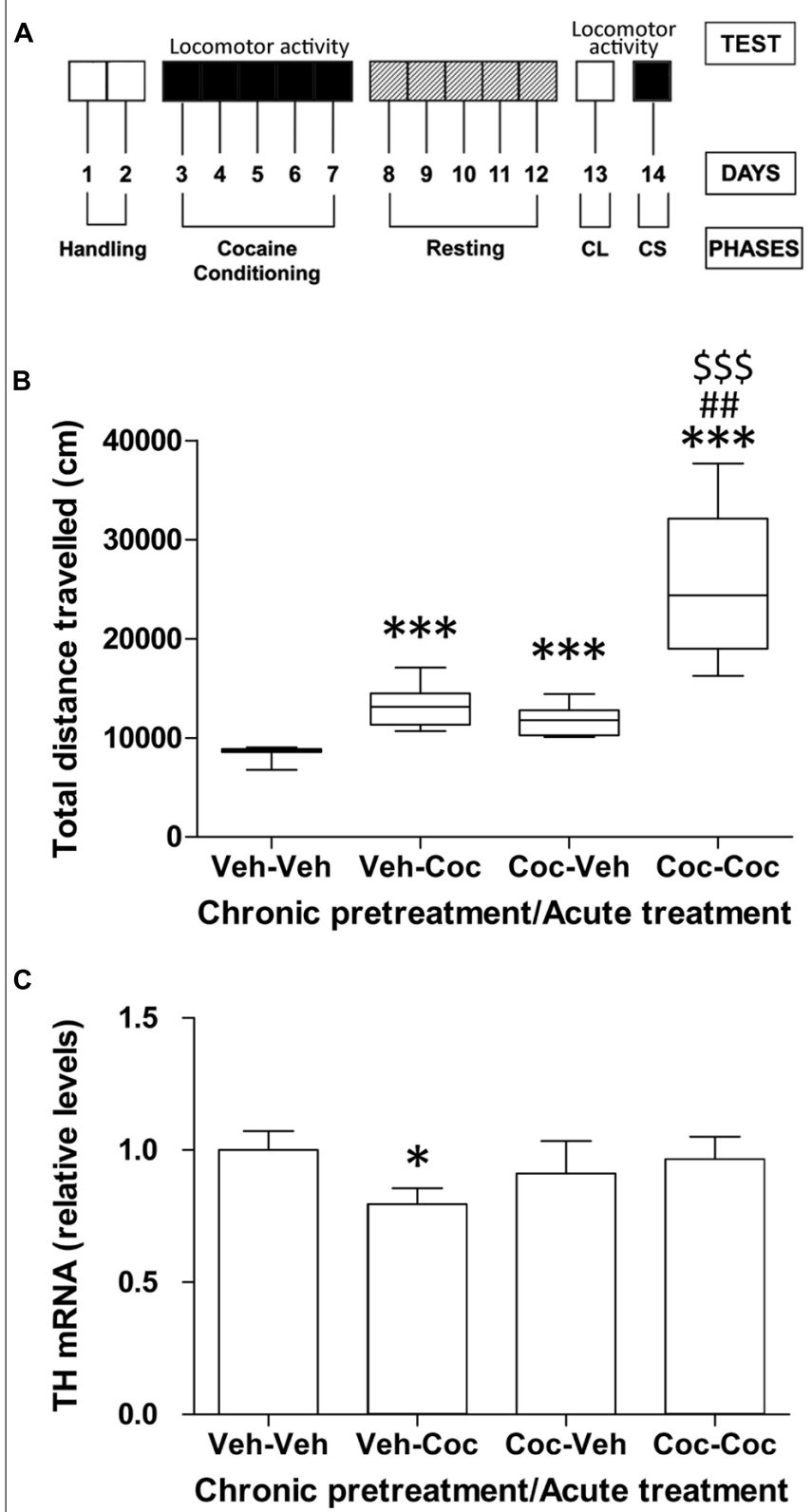

FIGURE 1 | (A) Schematic representation of the different phases of cocaine behavior such as acute cocaine administration $(10 \mathrm{mg} / \mathrm{kg})$, cocaine conditioning $(20 \mathrm{mg} / \mathrm{kg})$, resting, conditioned locomotion $(\mathrm{CL})$ and cocaine sensitization (CS, $10 \mathrm{mg} / \mathrm{kg}$ ). (B) Effect of acute cocaine administration (chronic vehicle + acute cocaine), CL (chronic cocaine + acute vehicle) and cocaine sensitization (chronic cocaine + acute cocaine) on distance traveled for 30 min measured in the Open Field. Box-and-whisker diagram represents the statistical distribution of the data ( $n=8 /$ group). Newman-Keuls: ${ }^{* * *} P<0.001$ vs. vehicle-vehicle group, ${ }^{\# \#} P<0.01$ vs. vehicle-cocaine group, $\$ \$ P<0.001$ vs. cocaine-vehicle group. (C) Relative mRNA levels of the catecholamine synthesizing enzyme tyrosine hydroxylase $(\mathrm{TH})$ in the mouse cerebellum after chronic pretreatment (vehicle and cocaine) and acute treatment (vehicle and cocaine). Histograms represent the mean $\pm \operatorname{SEM}(n=8 /$ group). Two-way ANOVA: ns, no significance. Bonferroni: $* P<0.05$ vs. vehicle-vehicle group. 
Western blot analysis showed that antibodies used against the components of the $\mathrm{eCB}$ signaling system revealed bands with expected molecular weights in the cerebellum, as was previously described (Suarez et al., 2008). CB1 immunoblotting revealed a prominent band at approximately $60 \mathrm{kD}$, NAPE-PLD at $46 \mathrm{kD}$, FAAH at $63 \mathrm{kD}, \mathrm{DAGL} \alpha$ at $120 \mathrm{kD}, \mathrm{DAGL} \beta$ at $76 \mathrm{kD}$, and MAGL at $35-37 \mathrm{kD}$.

\section{eCB mRNA levels in the cerebellum}

Two-way ANOVA analysis only showed a chronic pretreatment effect in CB1 gene expression $\left(F_{1,27}=10.73, \quad P=0.0029\right.$; Figure 2A). Significant effects of acute treatment were also found in the cerebellar gene expression of CB1 and DAGL $\alpha$ and the DAGL $\alpha /$ MAGL ratio $\left(\mathrm{CB} 1: F_{1,27}=5.66, P=0.024\right.$; DAGL $\alpha$ : $F_{1,27}=4.44, P=0.044$; DAGL $\alpha / \mathrm{MAGL}: F_{1,27}=16.52, P=0.0004$;
Figures $\mathbf{2 A}, \mathbf{D}, \mathbf{H})$. Interaction between factors was detected in the gene expression of $\mathrm{CB} 1$ and the DAGL $\alpha / \mathrm{MAGL}$ ratio $(\mathrm{CB} 1$ : $F_{1,27}=5.66, P=0.024$; DAGL $\alpha /$ MAGL: $F_{1,27}=4.57, P=0.041$; Figures 2A,H), indicating that acute treatment with cocaine did not have the same effect on the gene expression of CB1 and the DAGL $\alpha /$ MAGL ratio after chronic pretreatment. Bonferroni analysis showed that acute cocaine (vehicle-cocaine group) induced a decrease in CB1 gene expression ( $\left.{ }^{* *} P<0.01\right)$, DAGL $\alpha\left({ }^{*} P<0.05\right)$ and the DAGL $\alpha-\beta /$ MAGL ratio $\left({ }^{* *} P<0.001\right.$ and ${ }^{*} P<0.05$, respectively), but not in gene expression of NAPE-PLD, FAAH, DAGL $\beta$ and MAGL or the NAPE-PLD/FAAH ratio (Figure 2). Repeated cocaine-conditioned animals receiving vehicle (cocainevehicle group) or cocaine (cocaine-cocaine group) showed no effect on gene expression in the eCB signaling components analyzed compared with the vehicle-vehicle group. However, the

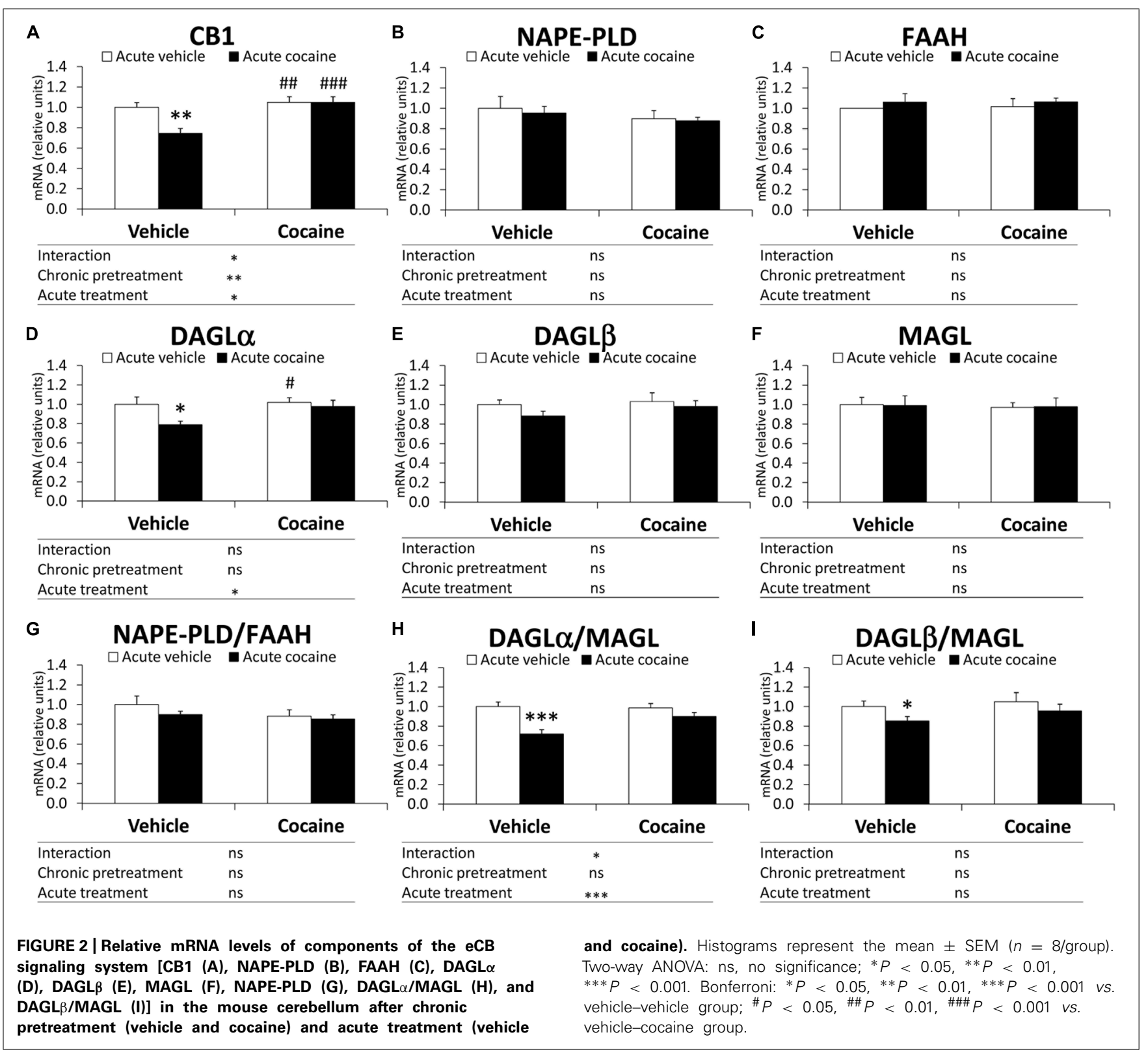


cerebella of the repeated cocaine-conditioned animals receiving vehicle presented increased CB1 and DAGL $\alpha$ mRNA levels ("\# $P<0.01$ and ${ }^{\#} P<0.05$, respectively), whereas repeated cocaine-conditioned animals receiving cocaine only showed an increase in CB1 mRNA levels ( ${ }^{\# \#} P<0.001$ ) compared with the vehicle-cocaine group (Figures 2A,D).

\section{eCB protein levels in the cerebellum}

Figure 3A illustrates representative immunoblots showing protein expression of the eCB components analyzed in the cerebellum of the four experimental groups $(\mathrm{V}-\mathrm{V}, \mathrm{V}-\mathrm{C}, \mathrm{C}-\mathrm{V}$, and $\mathrm{C}-\mathrm{C})$. Twoway ANOVA analysis showed a chronic pretreatment effect only in the NAPE-PLD/FAAH ratio $\left(F_{1,12}=10.31, P=0.0075\right)$ and DAGL $\beta /$ MAGL ratio $\left(F_{1,12}=6.02, P=0.0304\right.$; Figures $\left.3 \mathbf{H}, \mathbf{J}\right)$, but not in the remaining eCB components. A significant effect of acute treatment was not observed in the cerebellar protein expression of the eCB components analyzed. Interaction between factors was not detected, indicating that acute cocaine treatment had the same effect on the protein expression of the $\mathrm{eCB}$ components as chronic pretreatment. Bonferroni analysis showed that acute cocaine (vehicle-cocaine group) induced a decrease in the gene expression of DAGL $\alpha$, but not in the gene expression of the remaining eCB components and ratios analyzed (Figure 3 ). The cocainevehicle group showed an increase in the NAPE-PLD/FAAH ratio $\left({ }^{* *} P<0.01\right)$ and a decrease in the DAGL $\beta /$ MAGL $\left({ }^{*} P<0.05\right)$ ratio compared with the vehicle-vehicle group (Figures $\mathbf{3 H}, \mathbf{J}$ ). The cocaine-cocaine group showed lower protein expression of FAAH and DAGL $\beta$, a lower DAGL $\beta /$ MAGL ratio and a higher NAPE-PLD ratio compared with the vehicle-vehicle group $\left({ }^{*} P<0.05\right.$ in all cases; Figures 3D,F,H,J).

\section{GENE EXPRESSION OF GLUTAMATE SIGNALING COMPONENTS}

To address whether the cocaine behavior-related changes observed in $\mathrm{eCB}$ signaling components were associated with an alteration in the glutamatergic state, we analyzed the gene expression of the glutamate synthesizing enzymes LGA and KGA, mGluR3/5 metabotropic receptors, and NR1/2A/2B/2C-NMDA and GluR1/2/3/4-AMPA ionotropic receptor subunits in the cerebellum of the vehicle-vehicle $(\mathrm{V}-\mathrm{V})$, vehicle-cocaine $(\mathrm{V}-\mathrm{C})$, cocaine-vehicle $(\mathrm{C}-\mathrm{V})$, and cocaine-cocaine $(\mathrm{C}-\mathrm{C})$ mice.

Two-way ANOVA analysis showed a chronic pretreatment effect in the gene expression of NR1, GluR1 and GluR4 (NR1: $F_{1,28}=4.60, P=0.04$; GluR1: $F_{1,28}=5.49, P=0.026$; GluR4: $F_{1,28}=4.53, P=0.042$; Figures 4E,I,L). Significant effects of the acute treatment were only observed in the cerebellar gene expression of LGA $\left(F_{1,28}=4.30, P=0.047\right.$; Figure 4A). Interaction between factors was also found in the NR1, NR2A, NR2C and GluR1 mRNA levels (NR1: $F_{1,28}=9.17, P=0.0052$; NR2A: $F_{1,28}=6.31, P=0.018$; NR2C: $F_{1,28}=8.46, P=0.007$; GluR1: $F_{1,28}=5.20, P=0.0304$; Figures $\left.4 \mathrm{E}, \mathbf{F}, \mathbf{H}, \mathbf{I}\right)$, indicating that acute

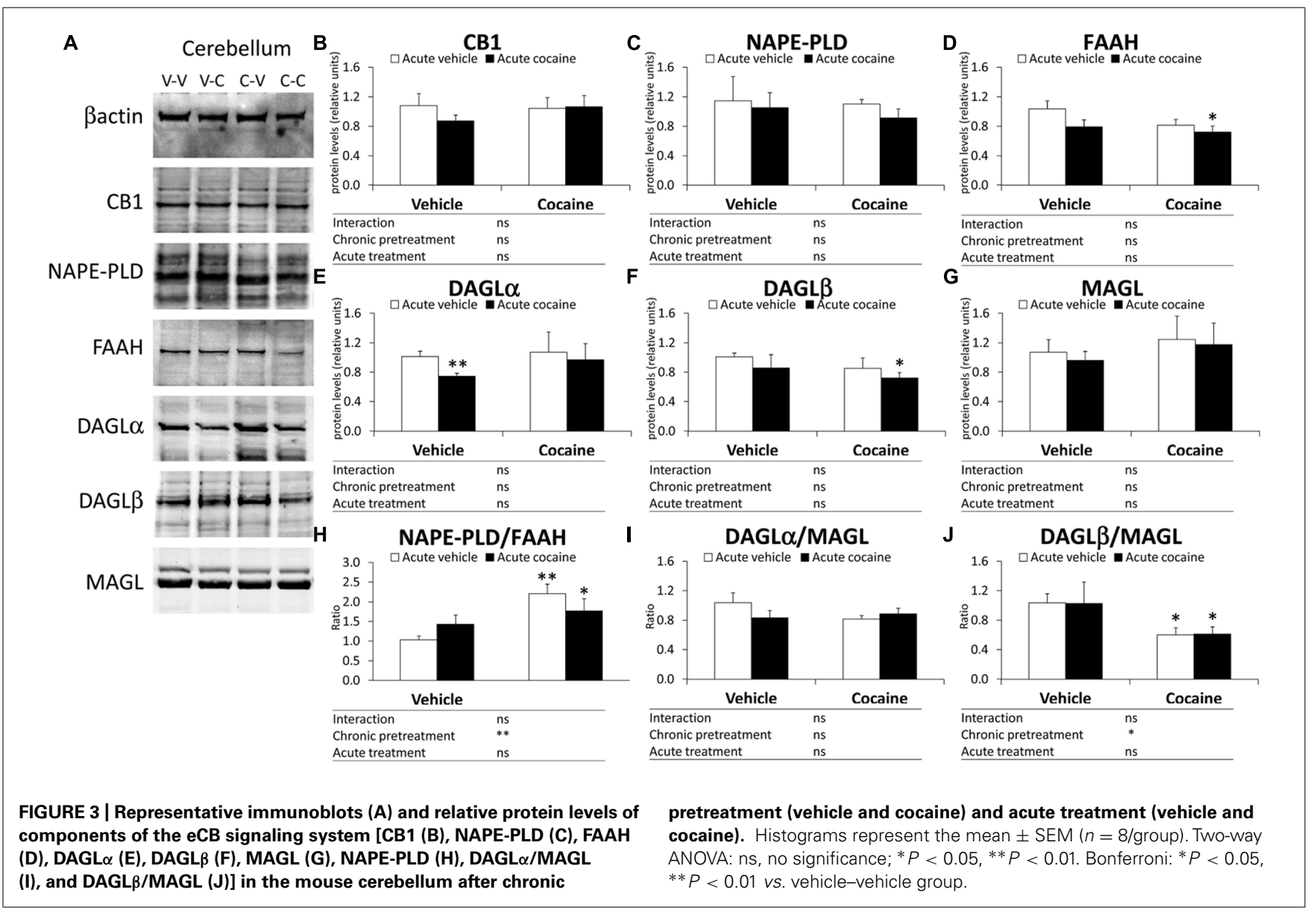


A

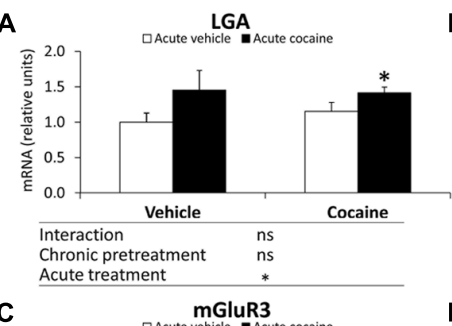

C
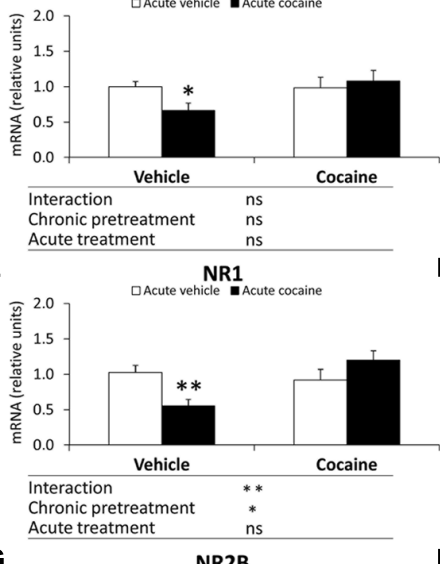

$\mathbf{G}$
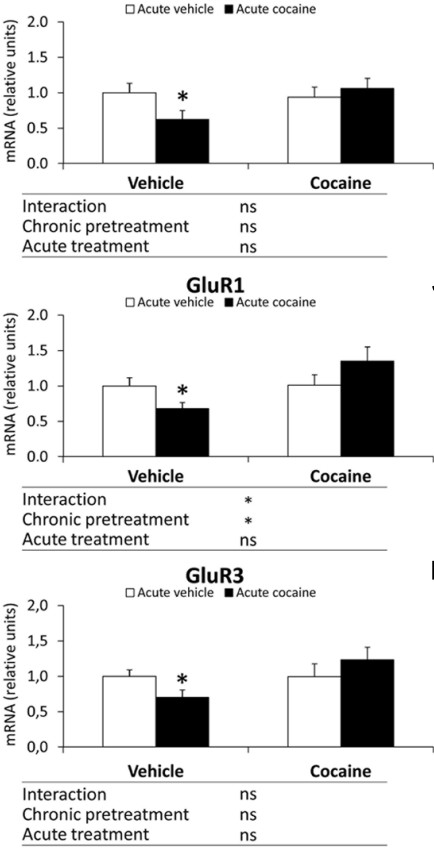

B
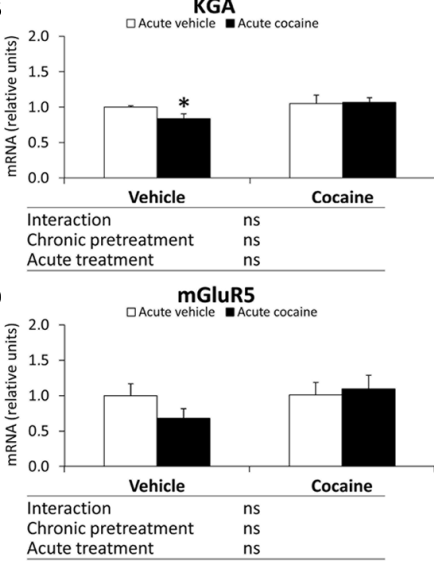

$\mathbf{F}$

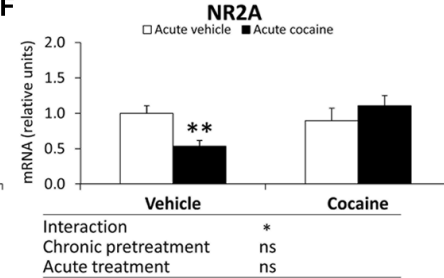

$\mathbf{H}$ treatment

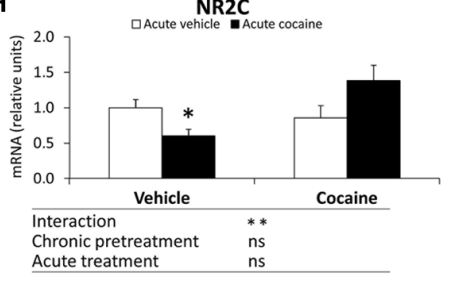

J

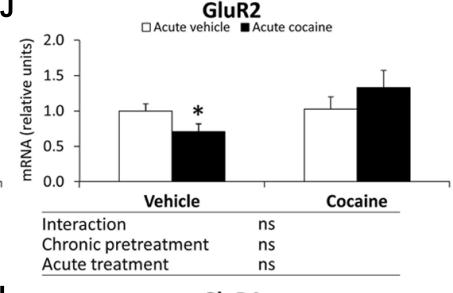

$\mathbf{L}$

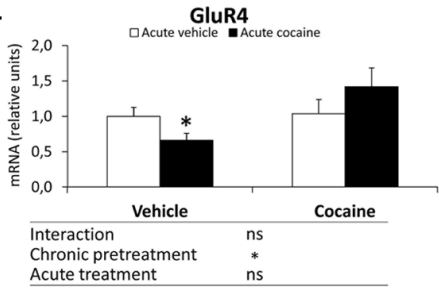

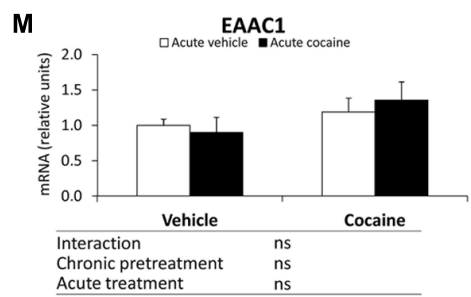

FIGURE 4 | Relative mRNA levels of components of the glutamate signaling system [LGA (A), KGA (B), mGluR3/5 (C,D), NR1/2A/2B/2C (E-H), and GluR1/2/3/4 (I-L) and EAAC1 (M)] in the mouse cerebellum after chronic pretreatment (vehicle and cocaine) and acute treatment (vehicle and cocaine). Histograms represent the mean \pm SEM ( $n=8 /$ group). Two-way ANOVA: ns, no significance; $* P<0.05, * * P<0.01$. Bonferroni: $* P<0.05, * * P<0.01$ vs. vehicle-vehicle group. 
treatment of cocaine differentially affects gene expression of NR1, NR2A, NR2C and GluR1 in a chronic pretreatment-dependent manner. Bonferroni analysis indicated that acute cocaine exposure (vehicle-cocaine group) induced a decrease in the gene expression of most glutamate signaling components analyzed, such as KGA $\left({ }^{*} P<0.05\right)$, mGluR3 $\left({ }^{*} P<0.05\right)$, NR1 $\left({ }^{* *} P<0.01\right)$, NR2A $\left({ }^{* *} P<0.01\right)$, NR2B $\left({ }^{*} P<0.05\right)$, NR2C $\left({ }^{*} P<0.05\right)$, GluR1( $\left.{ }^{*} P<0.05\right)$, GluR2 ( $\left.{ }^{*} P<0.05\right)$, GluR3 ( $\left.{ }^{*} P<0.05\right)$, and GluR4 $\left({ }^{*} P<0.05\right)$, compared with the vehicle-vehicle group (Figure 4). Repeated cocaine-conditioned animals receiving vehicle (cocaine-vehicle group) did not show any significant change in the gene expression of the glutamate components analyzed. Repeated cocaine-conditioned animals receiving cocaine (cocaine-cocaine group) only showed a significant increase in LGA mRNA levels compared with the vehicle-vehicle group $\left({ }^{*} P<0.05\right.$; Figure 4A).

\section{DISCUSSION}

The present study confirms that the eCB signaling system is a modulatory system that differentially modifies the expression of its components as a result of acute versus repeated cocaine exposure in the cerebellum. Overall, the data suggest that, in this central nervous system structure, acute cocaine exposure reduced the expression of the 2-AG-synthesizing enzyme DAGL $\alpha$. As a consequence, the ratio of DAGL $\alpha /$ MAGL dropped, suggesting reduced production of the endocannabinoid 2-AG, which is responsible for inhibiting the excitatory glutamatergic inputs of granule cells because DAGL $\alpha$ is expressed in Purkinje dendrites (Suarez et al., 2008). No changes were observed in the machinery that produces anandamide (AEA), the second major endocannabinoid. Repeated administration of cocaine resulted in a differential response in the 2-AG and AEA turnover machinery. Data associated with CS after chronic cocaine administration indicated decreased protein expression of FAAH and DAGL $\beta$ [production in Purkinje dendrites and cell bodies described by Suarez et al. (2008)], suggesting opposite availabilities for $N$-acylethanolamides (NAEs) and 2-AG, respectively. The lack of eCB-mediated inhibition might be partially responsible for the well-described hyperglutamatergic state associated with prolonged cocaine action (Cornish and Kalivas, 2000). Thus, after chronic cocaine exposure, we observed an activated glutamatergic state in the cerebellum as a consequence of increased expression of the glutamate synthetizing enzyme LGA and normalized expression of all metabotropic and ionotropic glutamate receptors. In contrast, after acute cocaine exposure, we observed a down-regulation of the expression of the glutamate synthetizing enzyme KGA, which can reflect a hypoactivated glutamatergic state in the cerebellum. This hypothetic hypoglutamatergic state was associated with decreased expression of key signaling receptors such as the metabotropic mGluR3 receptor and all subunits of both ionotropic (NMDA and AMPA) glutamate receptors. Because cerebellar circuits are involved in the control of motor planning, motor learning, execution and coordination, an intact endogenous cannabinoid system is required to regulate sensorimotor integration. Our hypothesis is as follows: (1) An excessive deficit of 2-AG production after acute cocaine exposure may facilitate glutamate-mediated activation of Purkinje inhibitory GABAergic transmission, leading to a compensatory hypoglutamatergic (biosynthesis of the enzyme KGA and glutamate receptors) state in the cerebellum. This dysregulation of both the $\mathrm{eCB}$ and glutamate signaling systems can result in disrupted control of action and coordination, especially in sensorimotor integration. (2) The decreased expression of the eCB-degradation FAAH and eCB-producer DAGL $\beta$, which suggest opposite tones for NAEs and 2-AG, respectively, could be explained by a neuroadaptation of the eCB signaling system to chronic cocaine exposure that finally leads to a hyperactivated glutamatergic state (biosynthesis enzyme LGA) in the cerebellum (see Table 2 for summary).

Analysis of the expression of the synthesis pathways for eCB revealed that DAGL $\alpha$ was reduced in the cerebellum of acute cocaine-exposed animals. The trend of the relative synthetizing/degrading enzymes suggested a decrease in 2-AG and no change in AEA. Because acute first exposure to cocaine increased

\section{Table 2 | Summary of the main effects observed on the endocannabinoid and glutamate systems after acute cocaine, conditioning locomotion, and cocaine sensitization ${ }^{\mathbf{1}}$.}

\begin{tabular}{|c|c|c|c|c|c|c|}
\hline \multirow{2}{*}{$\begin{array}{l}\text { Endocannabinoid system } \\
\text { mRNA/protein levels }\end{array}$} & \multicolumn{2}{|c|}{ Acute } & \multicolumn{2}{|c|}{$\begin{array}{l}\text { Conditioning } \\
\text { locomotion }\end{array}$} & \multicolumn{2}{|c|}{$\begin{array}{l}\text { Cocaine } \\
\text { sensitization }\end{array}$} \\
\hline & & & & & & \\
\hline CB1 & $\downarrow^{* *}$ & - & $\uparrow \# \#$ & - & $\uparrow \# \#$ & - \\
\hline NAPE-PLD & - & - & - & - & - & - \\
\hline FAAH & - & - & - & - & - & $\downarrow^{*}$ \\
\hline $\mathrm{DAGL} \alpha$ & $\downarrow^{*}$ & $\downarrow^{*}$ & $\uparrow \#$ & - & - & - \\
\hline$D A G L \beta$ & - & - & - & - & - & $\downarrow^{*}$ \\
\hline MAGL & - & - & - & - & - & - \\
\hline NAPE-PLD/FAAH & - & - & - & $\uparrow^{* *}$ & - & $\uparrow^{*}$ \\
\hline DAGL $\alpha / M A G L$ & $\downarrow^{* * *}$ & - & - & - & - & - \\
\hline DAGL $\beta / M A G L$ & $\downarrow^{*}$ & - & - & $\downarrow^{*}$ & - & $\downarrow^{*}$ \\
\hline \multicolumn{7}{|l|}{ Glutamatergic system } \\
\hline \multicolumn{7}{|l|}{ mRNA levels } \\
\hline LGA & \multicolumn{2}{|l|}{-} & \multicolumn{2}{|l|}{-} & \multicolumn{2}{|l|}{$\uparrow^{*}$} \\
\hline KGA & \multicolumn{2}{|l|}{$\downarrow^{*}$} & \multicolumn{2}{|l|}{-} & \multicolumn{2}{|l|}{-} \\
\hline mGluR3 & \multicolumn{2}{|l|}{$\downarrow^{*}$} & \multicolumn{2}{|l|}{-} & \multicolumn{2}{|l|}{-} \\
\hline mGluR5 & \multicolumn{2}{|l|}{-} & \multicolumn{2}{|l|}{-} & \multicolumn{2}{|l|}{-} \\
\hline NR1 & \multicolumn{2}{|l|}{$\downarrow^{* *}$} & \multicolumn{2}{|l|}{-} & \multicolumn{2}{|l|}{-} \\
\hline NR2A & \multicolumn{2}{|l|}{$\downarrow^{* *}$} & \multicolumn{2}{|l|}{-} & \multicolumn{2}{|l|}{-} \\
\hline NR2B & \multicolumn{2}{|l|}{$\downarrow^{*}$} & \multicolumn{2}{|l|}{-} & \multicolumn{2}{|l|}{-} \\
\hline NR2C & \multicolumn{2}{|l|}{$\downarrow^{*}$} & \multicolumn{2}{|l|}{-} & \multicolumn{2}{|l|}{-} \\
\hline GluR1 & \multicolumn{2}{|l|}{$\downarrow^{*}$} & \multicolumn{2}{|l|}{-} & - & \\
\hline GluR2 & $\downarrow^{*}$ & & - & & - & \\
\hline GluR3 & $\downarrow^{*}$ & & - & & - & \\
\hline GluR4 & $\downarrow^{*}$ & & - & & - & \\
\hline EAAC1 & - & & - & & - & \\
\hline $\mathrm{TH}$ & $\downarrow^{*}$ & & - & & - & \\
\hline
\end{tabular}

$1 * P<0.05,{ }^{* *} P<0.01,{ }^{* * *} P<0.001$ vs. vehicle-vehicle group; ${ }^{\#} P<0.05$, \#\# $P<0.01$ vs. vehicle-cocaine group. 
eCB formation, most likely via the activation of DA D2 receptors in the striatum (Giuffrida et al., 1999; Centonze et al., 2004), we hypothesized that, in the cerebellum, acute administration of cocaine might lead to a hyposensitization of the noradrenergicdriven (most likely beta-receptor mediated) eCB inhibitory signal and, as a consequence, a hyposensitization of the eCB-driven glutamatergic excitatory signal. There is strong evidence that eCBs modulate noradrenergic signaling (Kirilly et al., 2013). This signaling effect can be addressed by adapting the machinery needed for 2-AG (DAGL $\alpha$ ) and glutamate (KGA) production.

Regarding the adaptations observed in the $\mathrm{eCB}$ signaling system, acute cocaine caused a decrease in CB1 mRNA levels but, after chronic cocaine exposure, CB1 gene expression returned to initial levels (compared with the vehicle-vehicle group). Compared with the vehicle-cocaine group, prolonged exposure produced an increase in the CB1 gene (but not protein) expression in the cerebellum, which can be mainly associated with an increase in the NAPE-PLD/FAAH ratio and a decrease in the DAGL $\beta / M A G L$ ratio (observed at the protein level). This combination is suggestive of an increased availability of NAEs and a reduced availability of 2-AG, respectively, which may be induced by CS after chronic cocaine administration. Although a previous report indicated that enhanced bioavailability of AEA, derived from inhibition of either AEA uptake or AEA degradation, attenuated behavioral responses to cocaine (Chaperon et al., 1998; Fattore et al., 1999; Adamczyk et al., 2009), our results suggest that in the absence of external pharmacological manipulation of eCB production, endocannabinoid neuroadaptations are insufficient to compensate for the overactivity derived from chronic cocaine treatments. Thus, the up-regulation of CB1 gene expression (most likely associated with the local circuitry of the cerebellar cortex) and the increased availability of AEA cannot counteract glutamatergic overactivity. The decrease in 2-AG, which is the main retrograde signal, is not sufficiently compensated by enhanced AEA. Supporting this finding, a recent report by Orio and co-workers (Orio et al., 2009) showed that AEA and 2-AG release, as measured by microdialysis, was reduced in rats self-administering cocaine. This finding was associated with enhanced expression of $\mathrm{CB} 1$ receptors. In a previous study by our group (Rivera et al., 2013), we demonstrated a similar finding in the Hc of Lewis rats self-administering cocaine. Moreover, we cannot ignore the possibility that the observed changes in NAPE-PLD/FAAH may involve non-CB1-acting endocannabinoids, such as oleoylethanolamide (OEA). This interpretation arises because beta-adrenergic activation stimulates synthesis of OEA in response to cold exposure in adipocytes and to satiety in the small intestine (LoVerme et al., 2006; Fu et al., 2011). Moreover, OEA has been recently proposed to control cocaineassociated behaviors (Bilbao etal., 2013). Concerning the CB2 receptor, although we have not measured its expression in the present study, we cannot rule out a role for this receptor in the neuroadaptive responses to cocaine, as recently suggested (Xi et al., 2011; Aracil-Fernandez et al., 2012).

Glutamate seems to be a primary mediator of cocaine-induced behaviors associated with drug-seeking (Cornish and Kalivas, 2000). For instance, stimulation of glutamate receptors in the NAc augments the reinforcing effect of cocaine, and increased glutamatergic neurotransmission may be involved in facilitating relapse to cocaine-seeking behavior (Cornish et al., 1999). Activation of group I (mGluR1/5) metabotropic receptors resulted in an increase in NAc extracellular glutamate levels (Swanson et al., 2001). Moreover, stimulation of mGluR5 in the PFCx is sufficient to induce CS (Timmer and Steketee, 2012), whereas the administration of mGluR5 antagonists attenuated cocaine priming- and cue-induced reinstatement of cocaine seeking (Platt et al., 2008; Kumaresan et al., 2009). Our present data agree with these findings, suggesting the induction of glutamate synthesis (increased LGA gene expression) in CS after chronic cocaine exposure. However, the increase in the glutamate synthesizing enzyme LGA is not associated with an enhancement of the expression of any metabotropic or ionotropic glutamate receptor analyzed as a compensatory mechanism to counteract the putative hyperactivation of these receptors.

In summary, acute and chronic cocaine exposure differentially modulates the expression of the $\mathrm{eCB}$ and glutamate signaling machinery in the cerebellar cortex. After acute cocaine exposure, the changes are compatible with a situation in which the reduced inhibitory actions of $2-A G$ on glutamatergic terminals cause decreased synthesis of catecholamine and glutamate. After repeated cocaine exposure, increased synthesis of glutamate results from dysregulation of $\mathrm{eCB}$ availability (increased NAEs and decreased 2-AG) in the cerebellum. This situation can contribute to the induction of behavioral sensitization, a process thought to be relevant for psychostimulant addiction.

\section{ACKNOWLEDGMENTS}

This work was supported by Ministerio de Ciencia e Innovación [grant numbers SAF2010-19087, SAF 2010-20521], Instituto de Salud Carlos III, Ministerio de Economía y Competitividad, Red de Trastornos Adictivos [grant number RD12/0028/0001], CIBERobn, Plan Nacional Sobre Drogas, Ministerio de Sanidad y Consumo [grant number PNSD2010/143], Consejería de Economía, Innovación y Ciencia, Junta de Andalucía, UE/ERDF [grant number CTS-433, P-11-CVI-07637], Consejería de Salud, Junta de Andalucía [grant numbers PI0232/2008, PI0029/2008, SAS111224]. Juan Suárez is recipient of a "Miguel Servet" research contract from the National System of Health (Instituto de Salud Carlos III, grant number CP12/03109).

\section{REFERENCES}

Adamczyk, P., McCreary, A. C., Przegalinski, E., Mierzejewski, P., Bienkowski, P., and Filip, M. (2009). The effects of fatty acid amide hydrolase inhibitors on maintenance of cocaine and food self-administration and on reinstatement of cocaine-seeking and food-taking behavior in rats. J. Physiol. Pharmacol. 60, 119-125.

Aracil-Fernandez, A., Trigo, J. M., Garcia-Gutierrez, M. S., Ortega-Alvaro, A., Ternianov, A., Navarro, D., et al. (2012). Decreased cocaine motor sensitization and self-administration in mice overexpressing cannabinoid CB(2) receptors. Neuropsychopharmacology 37, 1749-1763. doi: 10.1038/npp. 2012.22

Bilbao, A., Blanco, E., Luque-Rojas, M. J., Suárez, J., Palomino, A., Vida, M., et al. (2013). Oleoylethanolamide dose-dependently attenuates cocaine-induced behaviours through a PPAR $\alpha$ receptor-independent mechanism. Addict. Biol. 18, 78-87. doi: 10.1111/adb.12006

Blanco, E., Campos-Sandoval, J. A., Palomino, A., Luque-Rojas, M. J., Bilbao, A., Suárez, J., et al. (2012). Cocaine modulates both glutaminase gene expression and glutaminase activity in the brain of cocaine-sensitized mice. Psychopharmacology (Berl.) 219, 933-944. doi: 10.1007/s00213-011-2418-x 
Bostan, A. C., and Strick, P. L. (2010). The cerebellum and basal ganglia are interconnected. Neuropsychol. Rev. 20, 261-270. doi: 10.1007/s11065-010-9143-9

Bower, J. M., and Parsons, L. M. (2003). Rethinking the "lesser brain." Sci. Am. 289, 50-57. doi: 10.1038/scientificamerican0803-48

Centonze, D., Battista, N., Rossi, S., Mercuri, N. B., Finazzi-Agro, A., Bernardi, G., et al. (2004). A critical interaction between dopamine D2 receptors and endocannabinoids mediates the effects of cocaine on striatal GABAergic Transmission. Neuropsychopharmacology 29, 1488-1497. doi: 10.1038/sj.npp.1300458

Chaperon, F., Soubrie, P., Puech, A. J., and Thiebot, M. H. (1998). Involvement of central cannabinoid (CB1) receptors in the establishment of place conditioning in rats. Psychopharmacology (Berl.) 135, 324-332. doi: 10.1007/s002130050518

Cornish, J. L., Duffy, P., and Kalivas, P. W. (1999). A role for nucleus accumbens glutamate transmission in the relapse to cocaine-seeking behavior. Neuroscience 93, 1359-1367. doi: 10.1016/S0306-4522(99)00214-6

Cornish, J. L., and Kalivas, P. W. (2000). Glutamate transmission in the nucleus accumbens mediates relapse in cocaine addiction. J. Neurosci. 20, RC89.

Couceyro, P., Pollock, K. M., Drews, K., and Douglass, J. (1994). Cocaine differentially regulates activator protein- 1 mRNA levels and DNA-binding complexes in the rat striatum and cerebellum. Mol. Pharmacol. 46, 667-676.

De Vries, T. J., and Schoffelmeer, A. N. (2005). Cannabinoid CB1 receptors control conditioned drug seeking. Trends Pharmacol. Sci. 26, 420-426. doi: 10.1016/j.tips.2005.06.002

Dietrich, J. B., Arpin-Bott, M. P., Kao, D., Dirrig-Grosch, S., Aunis, D., and Zwiller, J. (2007). Cocaine induces the expression of homer $1 \mathrm{~b} / \mathrm{c}$, homer $3 \mathrm{a} / \mathrm{b}$, and hsp 27 proteins in rat cerebellum. Synapse 61, 587-594. doi: 10.1002/syn.20412

Fattore, L., Martellotta, M. C., Cossu, G., Mascia, M. S., and Fratta, W. (1999). CB1 cannabinoid receptor agonist WIN55,212-2 decreases intravenous cocaine self-administration in rats. Behav. Brain Res. 104, 141-146. doi: 10.1016/S01664328(99)00059-5

Freund, T. F., Katona, I., and Piomelli, D. (2003). Role of endogenous cannabinoids in synaptic signaling. Physiol. Rev. 83, 1017-1066. doi: 10.1152/physrev.00004.2003

Fu, J., Dipatrizio, N. V., Guijarro, A., Schwartz, G. J., Li, X., Gaetani, S., et al. (2011). Sympathetic activity controls fat-induced oleoylethanolamide signaling in small intestine. J. Neurosci. 31, 5730-5736. doi: 10.1523/JNEUROSCI.5668-10.2011

Gerdeman, G. L., Ronesi, J., and Lovinger, D. M. (2002). Postsynaptic endocannabinoid release is critical to long-term depression in the striatum. Nat. Neurosci. 5 , 446-451. doi: 10.1038/nn832

Giuffrida, A., Parsons, L. H., Kerr, T. M., Rodriguez de Fonseca, F., Navarro, M., and Piomelli, D. (1999). Dopamine activation of endogenous cannabinoid signaling in dorsal striatum. Nat. Neurosci. 2, 358-363. doi: 10.1038/7268

Glowinski, J., and Axelrod, J. (1965). Effect of drugs on the uptake, release, and metabolism of H3-norepinephrine in the rat brain. J. Pharmacol. Exp. Ther. 149, $43-49$.

Gorriti, M. A., Rodriguez de Fonseca, F., Navarro, M., and Palomo, T. (1999). Chronic (-)-delta9-tetrahydrocannabinol treatment induces sensitization to the psychomotor effects of amphetamine in rats. Eur. J. Pharmacol. 365, 133-142. doi: 10.1016/S0014-2999(98)00851-6

Heath, R. G., Dempesy, C. W., Fontana, C. J., and Myers, W. A. (1978). Cerebellar stimulation: effects on septal region, hippocampus, and amygdala of cats and rats. Biol. Psychiatry 13, 501-529.

Jiménez-Rivera, C. A., Segarra, O., Jiménez, Z., and Waterhouse, B. D. (2000). Effects of intravenous cocaine administration on cerebellar Purkinje cell activity. Eur. J Pharmacol. 407, 91-100. doi: 10.1016/S0014-2999(00)00711-1

Kirilly, E., Hunyady, L., and Bagdy, G. (2013). Opposing local effects of endocannabinoids on the activity of noradrenergic neurons and release of noradrenaline: relevance for their role in depression and in the actions of $\mathrm{CB}(1)$ receptor antagonists. J. Neural Transm. 120, 177-186. doi: 10.1007/s00702-0120900-1

Kumaresan, V., Yuan, M., Yee, J., Famous, K. R., Anderson, S. M., Schmidt, H. D., et al. (2009). Metabotropic glutamate receptor 5 (mGluR5) antagonists attenuate cocaine priming- and cue-induced reinstatement of cocaine seeking. Behav. Brain Res. 202, 238-244. doi: 10.1016/j.bbr.2009.03.039

LoVerme, J., Guzmán, M., Gaetani, S., and Piomelli, D. (2006). Cold exposure stimulates synthesis of the bioactive lipid oleoylethanolamide in rat adipose tissue. J. Biol. Chem. 281, 22815-22818. doi: 10.1074/jbc.M604751200

Lopez-Moreno, J. A., Gonzalez-Cuevas, G., Moreno, G., and Navarro, M. (2008). The pharmacology of the endocannabinoid system: functional and structural interactions with other neurotransmitter systems and their repercussions in behavioral addiction. Addict. Biol. 13, 160-187. doi: 10.1111/j.13691600.2008.00105.x

Maldonado, R., Valverde, O., and Berrendero, F. (2006). Involvement of the endocannabinoid system in drug addiction. Trends Neurosci. 29, 225-232. doi: 10.1016/j.tins.2006.01.008

Malenka, R. C., and Bear, M. F. (2004). LTP and LTD: an embarrassment of riches. Neuron 44, 5-21. doi: 10.1016/j.neuron.2004.09.012

Mathur, B. N., Tanahira, C., Tamamaki, N., and Lovinger, D. M. (2013). Voltage drives diverse endocannabinoid signals to mediate striatal microcircuit-specific plasticity. Nat. Neurosci. 16, 1275-1283. doi: 10.1038/nn.3478

Mereu, M., Tronci, V., Chun, L. E., Thomas, A. M., Green, J. L., Katz, J. L., et al. (2013). Cocaine-induced endocannabinoid release modulates behavioral and neurochemical sensitization in mice. Addict. Biol. doi: 10.1111/adb. 12080 [Epub ahead of print].

Miquel, M., Toledo, R., García, L. I., Coria-Avila, G. A., and Manzo, J. (2009). Why should we keep the cerebellum in mind when thinking about addiction? Curr. Drug Abuse Rev. 2, 26-40. doi: 10.2174/1874473710902010026

Nestler, E. J. (2005). Is there a common molecular pathway for addiction? Nat. Neurosci. 8, 1445-1449. doi: 10.1038/nn1578

Noori, H. R., Spanagel, R., and Hansson, A. C. (2012). Neurocircuitry for modeling drug effects. Addict. Biol. 17, 827-864. doi: 10.1111/j.1369-1600.2012. 00485.x

Orio, L., Edwards, S., George, O., Parsons, L. H., and Koob, G. F. (2009). A role for the endocannabinoid system in the increased motivation for cocaine in extendedaccess conditions. J. Neurosci. 29, 4846-4857. doi: 10.1523/JNEUROSCI.056309.2009

Paxinos, G., and Franklin, K. B. J. (2004). The Mouse Brain in Stereotaxic Coordinates, Compact 2nd Edn. Amsterdam: Elsevier Academic Press.

Piomelli, D. (2003). The molecular logic of endocannabinoid signalling. Nat. Rev. Neurosci. 4, 873-884. doi: 10.1038/nrn1247

Pitts, D. K., and Marwah, J. (1987). Neuropharmacology of cocaine: role of monoaminergic systems. Monogr. Neural Sci. 13, 34-54.

Platt, D. M., Rowlett, J. K., and Spealman, R. D. (2008). Attenuation of cocaine self-administration in squirrel monkeys following repeated administration of the mGluR5 antagonist MPEP: comparison with dizocilpine. Psychopharmacology (Berl.) 200, 167-176. doi: 10.1007/s00213-008-1191-y

Rivera, P., Miguens, M., Coria, S. M., Rubio, L., Higuera-Matas, A., BermudezSilva, F. J., et al. (2013). Cocaine self-administration differentially modulates the expression of endogenous cannabinoid system-related proteins in the hippocampus of Lewis vs. Fischer 344 rats. Int. J. Neuropsychopharmacol. 16, 1277-1293. doi: $10.1017 /$ S1461145712001186

Ronesi, J., and Lovinger, D. M. (2005). Induction of striatal long-term synaptic depression by moderate frequency activation of cortical afferents in rat. J. Physiol. 562(Pt 1), 245-256. doi: 10.1113/jphysiol.2004.068460

Ruiz, A., Campanac, E., Scott, R. S., Rusakov, D. A., and Kullmann, D. M. (2010). Presynaptic GABAA receptors enhance transmission and LTP induction at hippocampal mossy fiber synapses. Nat. Neurosci. 13, 431-438. doi: $10.1038 / \mathrm{nn} .2512$

Schweighofer, N., Doya, K., and Kuroda, S. (2004). Cerebellar aminergic neuromodulation: towards a functional understanding. Brain Res. Brain Res. Rev. 44, 103-116. doi: 10.1016/j.brainresrev.2003.10.004

Suarez, J., Bermudez-Silva, F. J., Mackie, K., Ledent, C., Zimmer, A., Cravatt, B. F., et al. (2008). Immunohistochemical description of the endogenous cannabinoid system in the rat cerebellum and functionally related nuclei. J. Comp. Neurol. 509, 400-421. doi: 10.1002/cne.21774

Swanson, C. J., Baker, D. A., Carson, D., Worley, P. F., and Kalivas, P. W. (2001) Repeated cocaine administration attenuates group I metabotropic glutamate receptor-mediated glutamate release and behavioral activation: a potential role for Homer. J. Neurosci. 21, 9043-9052.

Szumlinski, K. K., Abernathy, K. E., Oleson, E. B., Klugmann, M., Lominac, K. D., He, D. Y., et al. (2006). Homer isoforms differentially regulate cocaine-induced neuroplasticity. Neuropsychopharmacology 31, 768-777. doi: 10.1038/sj.npp. 1300890

Timmer, K. M., and Steketee, J. D. (2012). Examination of a role for metabotropic glutamate receptor 5 in the medial prefrontal cortex in cocaine sensitization in rats. Psychopharmacology (Berl.) 221, 91-100. doi: 10.1007/s00213-0112548-1 
Waterhouse, B. D., Stowe, Z. N., Jimenez-Rivera, C. A., Sessler, F. M., and Woodward, D. J. (1991). Cocaine actions in a central noradrenergic circuit: enhancement of cerebellar Purkinje neuron responses to iontophoretically applied GABA. Brain Res. 546, 297-309. doi: 10.1016/0006-8993(91)91494-L

Xi, Z. X., Peng, X. Q., Li, X., Song, R., Zhang, H. Y., Liu, Q. R., et al. (2011). Brain cannabinoid $\mathrm{CB}(2)$ receptors modulate cocaine's actions in mice. Nat. Neurosci. 14, 1160-1166. doi: 10.1038/nn.2874

Yamaguchi, M., Suzuki, T., Abe, S., Hori, T., Kurita, H., Asada, T., et al. (2002). Repeated cocaine administration differentially affects NMDA receptor subunit (NR1, NR2A-C) mRNAs in rat brain. Synapse 46, 157-169. doi: $10.1002 /$ syn. 10132

Conflict of Interest Statement: The authors declare that the research was conducted in the absence of any commercial or financial relationships that could be construed as a potential conflict of interest.
Received: 06 December 2013; accepted: 17 February 2014; published online: 05 March 2014.

Citation: Palomino A, Pavón F-J, Blanco-Calvo E, Serrano A, Arrabal S, Rivera P, Alén F, Vargas A, Bilbao A, Rubio L, Rodríguez de Fonseca F and Suárez J (2014) Effects of acute versus repeated cocaine exposure on the expression of endocannabinoid signaling-related proteins in the mouse cerebellum. Front. Integr. Neurosci. 8:22. doi: 10.3389/fnint.2014.00022

This article was submitted to the journal Frontiers in Integrative Neuroscience.

Copyright (c) 2014 Palomino, Pavón, Blanco-Calvo, Serrano, Arrabal, Rivera, Alén, Vargas, Bilbao, Rubio, Rodríguez de Fonseca and Suárez. This is an open-access article distributed under the terms of the Creative Commons Attribution License (CC BY). The use, distribution or reproduction in other forums is permitted, provided the original author(s) or licensor are credited and that the original publication in this journal is cited, in accordance with accepted academic practice. No use, distribution or reproduction is permitted which does not comply with these terms. 